Pacific Journal of Mathematics

ON COUNTABLE PRODUCTS AND ALGEBRAIC
CONVEXIFICATIONS OF PROBABILISTIC METRIC SPACES 


\title{
ON COUNTABLE PRODUCTS AND ALGEBRAIC CONVEXIFICATIONS OF PROBABILISTIC METRIC SPACES
}

\section{Claudi Alsina}

\begin{abstract}
Two different ways of defining a probabilistic metric on the countable product of a family of probabilistic metric spaces are studied and compared. The algebraic convexification of probabilistic metric spaces is also investigated.
\end{abstract}

o. Introduction. Finite products of probabilistic metric (PM) spaces have been studied previously by R. Egbert [1], R. Tardiff [10], A. Xavier [13] and V. Istratescu and I. Vaduva [2]. In this paper we turn to the study of countable products.

If $\left\{\left(S_{i}, \mathscr{F}^{i}, \tau_{i}\right) \mid i \in N\right\}$ is a family of PM spaces and if we form the generalized metric space $\left(\prod_{i=1}^{\infty} S_{i}, \prod_{i=1}^{\infty} \Delta^{+}, \prod_{i=1}^{\infty} \tau_{i}\right)$ in the sense of E. Trillas $[11,12]$, then the problem is to choose the most satisfactory assignment of a probability distribution function in $\Delta^{+}$to each member of the family $\left(\mathscr{F}^{i}\right)$, i.e., to each sequence $\left(F_{i}\right) \in \prod_{i=1}^{\infty} \Delta^{+}$. Two natural assignments are considered:

(a) The series $\sum_{i=1}^{\infty}\left(1 / 2^{i}\right) F_{i}$ as the weak limit of the pointwise nondecreasing sequence $\left\{\sum_{i=1}^{n}\left(1 / 2^{i}\right) F_{i} \mid n \in N\right\}$ in $\Delta^{+}$.

(b) The product $\tau_{i=1}^{\infty} F_{i}$ as the weak limit of the pointwise nonincreasing sequence $\left\{\tau\left(F_{1}, \cdots, F_{n}\right) \mid n \in N\right\}$ in $\Delta^{+}$, where $\tau$ is an arbitrary triangle function.

In case (a) we speak of $\Sigma$-products and in case (b) of $\tau$-products.

In addition we also consider the question of the algebraic convexification of a PM space, which involves the embedding of the given space a in convex subspace of a suitably defined countable product.

Throughout the paper we assume that the reader is familiar with the basic definitions and concepts of the theory of PM spaces as given, e.g., in [8] or [10].

\section{On $\Sigma$-products. We begin with the following:}

Definition 1.1. Let $\left\{\left(S_{i}, \mathscr{F}^{i}, \tau_{i}\right) \mid i \in N\right\}$ be a countable family of PM spaces. The $\Sigma$-product of this family is the space $\left(\prod_{i=1}^{\infty} S_{i}, \mathscr{F}^{\Sigma}\right)$, where $\mathscr{F}^{\Sigma}: \prod_{i=1}^{\infty} S_{i} \times \prod_{i=1}^{\infty} S_{i} \rightarrow \Delta^{+}$, is the mapping given by $\mathscr{F}^{\Sigma}\left(\left(p_{i}\right),\left(q_{i}\right)\right)=\sum_{i=1}^{\infty}\left(1 / 2^{i}\right) \mathscr{F}^{i}\left(p_{i}, q_{i}\right)$, for any sequences $\left(p_{i}\right)$ and $\left(q_{i}\right)$ in $\prod_{i=1}^{\infty} S_{i}$.

In this section we will use the abbreviations: $S=\prod_{i=1}^{\infty} S_{i}, F=$ $\mathscr{F}^{\Sigma}, F_{\overline{p q}}=\mathscr{F}^{\Sigma}\left(\left(p_{i}\right),\left(q_{i}\right)\right)$ and $F_{p_{i} q_{i}}=\mathscr{F}^{i}\left(p_{i}, q_{i}\right)$. 
THeORem 1.1. The $\Sigma$-product $(S, F)$ is a $P M$ space, more precisely, a Menger space under the t-norm $T_{w}$.

Proof. We have to show: (1) $F_{\overline{p q}}=\varepsilon_{0}$ if and only if $\bar{p}=\bar{q}$, where $\varepsilon_{0} \in \Delta^{+}$is given by

$$
\varepsilon_{0}(x)= \begin{cases}0, & \text { if } x \leqq 0 \\ 1, & \text { if } x>0\end{cases}
$$

(2) $F_{\overline{p q}}=F_{\overline{q p}}$, and (3) if $F_{\overline{p q}}(x)=1$ and $F_{\bar{q} \bar{r}}(y)=1$ then $F_{\bar{p} r}(x+y)=1$. Since $\sum_{i=1}^{\infty}\left(a_{i} / 2^{i}\right)=1$ if and only if each $a_{i}=1$ (when $a_{i} \in[0,1]$, for each $i \in N)$, the verification of (1), (2), and (3) is immediate.

TheOREM 1.2. The $\Sigma$-product $(S, F)$ is a $P M$ space under the triangle function $\tau_{T_{m}}$ whenever each $\left(S_{i}, \mathscr{F}^{i}, \tau_{i}\right)$ is such that $\tau_{i} \geqq \tau_{T_{m}}$.

Proof. In view of (1) and (2) of Theorem 1.1, we need only prove the triangle inequality. Let $x, y \geqq 0$ and $\bar{p}, \bar{q}, \bar{r}$ in $S$ be given. Then

$$
\begin{aligned}
& T_{m}\left(F_{\bar{p} \bar{q}}(x), F_{\bar{q} \bar{r}}(y)\right)=\operatorname{Max}\left(F_{\bar{p} \bar{q}}(x)+F_{\bar{q} \bar{r}}(y)-1,0\right) \\
& \quad=\operatorname{Max}\left(\sum_{i=1}^{\infty} 2^{-i}\left(F_{p_{i} q_{i}}(x)+F_{q_{i} r_{i}}(y)-1\right), 0\right) \\
& \quad \leqq \sum_{i=1}^{\infty} 2^{-i} \operatorname{Max}\left(F_{p_{i} q_{i}}(x)+F_{q_{i} r_{i}}(y)-1,0\right) \\
& \quad=\sum_{i=1}^{\infty} 2^{-i} T_{m}\left(F_{p_{i} q_{i}}(x), F_{q_{i} r_{i}}(y)\right) \leqq \sum_{i=1}^{\infty} 2^{-i} F_{p_{i} r_{i}}(x+y)=F_{\overline{p r}}(x+y),
\end{aligned}
$$

where in the last inequality we have used the fact that for every $i \in N$,

$$
\begin{aligned}
T_{m}\left(F_{p_{i} q_{i}}(x), F_{q_{i} r_{i}}(y)\right) & \leqq \tau_{T_{m}}\left(F_{p_{i} q_{i}}, F_{q_{i} r_{i}}\right)(x+y) \\
& \leqq \tau_{i}\left(F_{p_{i} q_{i}}, F_{q_{i} r_{i}}\right)(x+y) \leqq F_{p_{i} r_{i}}(x+y) .
\end{aligned}
$$

Thus for any $t \geqq 0, \tau_{T_{m}}\left(F_{\bar{p} \bar{q}}, F_{\bar{q} \bar{r}}\right)(t)=\sup _{x+y=t} T_{m}\left(F_{\bar{p} \bar{q}}(x), F_{\bar{q} \bar{r}}(y)\right) \leqq F_{\bar{p} \bar{r}}(t)$.

Following the lines of the above proof it is easy to see that the $\Sigma$-product $(S, F)$ is a PM space under the triangle function $\Pi_{T_{m}}$ whenever each $\left(S_{i}, \mathscr{F}^{i}, \tau_{i}\right)$ is such that $\tau_{i} \geqq \Pi_{T_{m}}$.

Since the most common $t$-norms are stronger than $T_{m}$ (e.g., $T_{m} \leqq$ Prod $\leqq$ Min) it follows that Theorem 1.2 applies to a large class of PM spaces. However $T_{m}$ cannot be replaced by a stronger $t$-norm, whence, for triangle functions of the form $\tau_{r}$, the result of Theorem 1.2 is best-possible. This is a consequence of:

THEOREM 1.3. Let $T$ be a t-norm and suppose that 


$$
T\left(\sum_{i=1}^{\infty} \frac{a_{i}}{2^{i}}, \sum_{i=1}^{\infty} \frac{b_{i}}{2^{i}}\right) \leqq \sum_{i=1}^{\infty} \frac{1}{2^{i}} T\left(a_{i}, b_{i}\right)
$$

for any sequences $\left(a_{i}\right),\left(b_{i}\right)$ in $[0,1]$. Then $T_{w} \leqq T \leqq T_{m}$.

Proof. Note first that $T_{w}$ satisfies (1.2). Similarly, the fact that $T_{m}$ satisfies (1.2) is the crucial point in the proof of Theorem 1.2. Now suppose $T$ satisfies (1.2). Since $T$ is always stronger than $T_{w}$ and since $T=T_{m}$ on the boundary of the unit square, we must show $T \leqq T_{m}$ on $(0,1) \times(0,1)$. To this end, let $B_{0}=0$ and, for any $n \geqq 1$, let $B_{n}=1 / 2+\cdots+1 / 2^{n}$ and consider the partition $(0,1) \times$ $(0,1)=R_{1} \cup \bigcup_{n=2}^{\infty} R_{n}$, where

$$
R_{1}=\{(x, y) \mid 0<x, y<1, x+y \leqq 1\}
$$

and

$$
R_{n}=\left\{(x, y) \mid 0<x, y<1,1+B_{n-2}<x+y \leqq 1+B_{n-1}\right\} .
$$

Let $(x, y) \in R_{1}$ be such that $x+y=1$, and let $\sum_{i=1}^{\infty}\left(a_{i} / 2^{i}\right)$ be any binary expansion of $x$, i.e., $x=\sum_{i=1}^{\infty}\left(a_{i} / 2^{i}\right)$, where $a_{i} \in\{0,1\}$, for each $i$. Then noting that $T(1,0)=T(0,1)=0$ and using (1.2) we have

$$
T(x, y)=T(x, 1-x)=T\left(\sum_{i=1}^{\infty} \frac{a_{i}}{2^{i}}, \sum_{i=1}^{\infty} \frac{1-a_{i}}{2^{i}}\right) \leqq \sum_{i=1}^{\infty} \frac{1}{2^{i}} T\left(a_{i}, 1-a_{i}\right)=0 .
$$

Thus since $T$ is nondecreasing, $T(x, y)=T_{m}(x, y)=0$ for all $(x, y)$ in $R_{1}$.

Now fix $n \geqq 2$ and consider any point $(x, y) \in R_{n}$. Then $x+y=$ $1+B_{n-2}+a$, where $0<a \leqq 1 / 2^{n-1}$, so that at least one of $x, y$ must be greater than $B_{n-1}$.

Suppose $x=B_{n-1}+\sum_{i=n}^{\infty}\left(x_{i} / 2^{i}\right)$, where $x_{i} \in\{0,1\}$ for each $i$. Then since $1-B_{n-1}=1 / 2^{n-1}$, we have

$$
\begin{aligned}
y & =1+B_{n-2}+a-x=B_{n-2}+a+1 / 2^{n-1}-\sum_{i=n}^{\infty} x_{i} / 2^{i} \\
& =B_{n-2}+2^{n-1} a / 2^{n-1}+\sum_{i=n}^{\infty}\left(1-x_{i}\right) / 2^{i} .
\end{aligned}
$$

Consequently, writing

$$
x=B_{n-2}+1 / 2^{n-1}+\sum_{i=n}^{\infty} x_{i} / 2^{i},
$$

and then using (1.2) and the fact that $T(1,1)=1$, yields

$$
\begin{aligned}
T(x, y) & \leqq B_{n-2}+\frac{1}{2^{n-1}} T\left(1,2^{n-1} a\right)+\sum_{i=n}^{\infty} \frac{1}{2^{i}} T\left(x_{i}, 1-x_{i}\right) \\
& =B_{n-2}+a=x+y-1=T_{m}(x, y) .
\end{aligned}
$$


If $x<B_{n-1}$, then reversing the roles of $x$ and $y$ yields the same conclusion, and this completes the proof.

It should be noted that neither the commutativity nor associativity of $T$ was used in the above proof. Thus we have in fact established:

COROLllaRY 1.1. Let $T:[0,1] \times[0,1] \rightarrow[0,1]$ be nondecreasing in each place and such that $T(0, x)=T(x, 0)=0$ and $T(x, 1)=$ $T(1, x)=x$, for any $x$ in $[0,1]$. Suppose $T$ satisfies (1.2). Then $T_{w} \leqq T \leqq T_{m}$.

The converse of Corollary 1.1 is false as the following example shows.

Example 1.1. For any $\lambda \in[0,1]$ consider the function $T_{\lambda}:[0,1] \times$ $[0,1] \rightarrow[0,1]$ defined by

$$
T_{\lambda}(x, y)= \begin{cases}T_{m}(x, y), & \text { if } x+y \leqq 1+\lambda \text { or } x=1 \text { or } y=1, \\ \lambda, & \text { otherwise. }\end{cases}
$$

If $0 \leqq \mu<\lambda \leqq 1$, we have $T_{w}=T_{0} \leqq T_{\mu}<T_{\lambda} \leqq T_{1}=T_{m}$. Let $0<$ $\lambda<1$. Then there is an $n \in N$ such that $\lambda<1-2^{-(n-1)}<1$ and consequently an $a \in(0,1]$ such that $(1+\lambda)\left(2-2^{-(n-1)}\right)^{-1}<a<1$. Hence

$$
\begin{aligned}
T_{\lambda}\left(\sum_{i=1}^{n} \frac{a}{2^{i}}, \sum_{i=1}^{n} \frac{a}{2^{i}}\right) & =T_{\lambda}\left(a\left(1-2^{-n}\right), a\left(1-2^{-n}\right)\right) \\
& =\lambda=T_{\lambda}(a, a)>\sum_{i=1}^{n} \frac{1}{2^{i}} T_{\lambda}(a, a) .
\end{aligned}
$$

Thus whenever $0<\lambda<1$, (1.2) fails for $T_{\lambda}$.

Since the functions $T_{\lambda}$ defined above are not associative, Example 1.1 is not a complete counterexample of Theorem 1.3. A $t$-norm weaker than $T_{m}$ violating (1.2) remains to be found. Indeed, there is good reason to conjecture that any continuous $t$-norm weaker than $T_{m}$, satisfies (1.2).

As a consequence of Theorem 1.3 it is to be expected that, even in the case of a family of PM spaces under the same $t$-norm $T$, the $\Sigma$-product need not be a PM space under $T$. The next two examples show that this is indeed the case.

EXAMPLE 1.2. The $\Sigma$-product of Wald spaces is not necessarily a Wald space. 
For any $a \geqq 0$, let $\varepsilon_{a}(x)=\varepsilon_{0}(x-a)$, where $\varepsilon_{0}$ is given by (1.1). Consider the metric space $\left(\boldsymbol{R}^{+},||\right)$as a Wald space $\left(\boldsymbol{R}^{+}, G,{ }^{*}\right)$, where $G_{p q}=\varepsilon_{|p-q|}$ for all $p, q \in \boldsymbol{R}^{+}$. Let $\left(S_{i}, \mathscr{F}^{i}, \tau_{i}\right)=\left(\boldsymbol{R}^{+}, G,{ }^{*}\right)$ for each $i$ and form the $\Sigma$-product $\left(\prod_{i=1}^{\infty} \boldsymbol{R}^{+}, F, \tau_{T_{m}}\right)$. Choose $\bar{p}=(0), \bar{q}=$ $(1,0,0, \cdots), \quad \bar{r}=(1) . \quad$ Then $F_{\overline{p q}}=F_{\bar{q} \bar{r}}=1 / 2\left(\varepsilon_{1}+\varepsilon_{0}\right), \quad F_{\bar{p} \bar{r}}=\varepsilon_{1}$, and $F_{\overline{p q}} * F_{\bar{q} \bar{r}}=1 / 4 \varepsilon_{2}+1 / 2 \varepsilon_{1}+1 / 4 \varepsilon_{0}$, whence for $0<x<1, F_{\overline{p q}} * F_{\bar{q} \bar{r}}>F_{\bar{p} \bar{r}}$.

EXAMPLE 1.3. The $\Sigma$-product of simple spaces is not necessarily a simple space.

Let each component space be the simple space $\left(\boldsymbol{R}^{+}, d, G\right)$ generated by the metric $d(x, y)=|x-y| / 1+|x-y|$ and a distribution function $G \in \mathscr{D}^{+}$such that $G(1)<1 / 2$.

In the $\Sigma$-product $\left(\prod_{i=1}^{\infty} R^{+}, F, \tau_{T_{m}}\right)$ we have $F_{\bar{p} \bar{q}}(x)=\sum_{i=1}^{\infty} 1 / 2^{i} G_{p_{i} q_{i}}(x)$, where for every $i \geqq 1, G_{p_{i} q_{i}}(x)=G\left(x / d\left(p_{i}, q_{i}\right)\right)$ if $p_{i} \neq q_{i}$ and $G_{p_{i} q_{i}}(x)=$ $\varepsilon_{0}(x)$ if $p_{i}=q_{i}$. Choose $\bar{p}=(0), \bar{q}=(0,2,3,4, \cdots, n, \cdots)$ and $\bar{r}=$ $(1,2,3, \cdots, n, \cdots)$. Then $F_{\bar{p} \bar{q}}(1 / 4) \geqq 1 / 2, F_{\bar{q} r}(1 / 4) \geqq 1 / 2$ but $F_{\overline{p r}}(1 / 2)<$ $1 / 2$. Thus the $\Sigma$-product is not a Menger space under Min. Consequently it cannot be a simple space.

One of the most interesting facts about $\Sigma$-products is given in the following:

TheOREM 1.4. Let $\left\{\left(S_{i}, \mathscr{F}^{i}, \tau_{i}\right) \mid i \in N\right\}$ and $(S, F)$ be as in Theorem 1.2. Let each $S_{i}$ be endowed with the $\varepsilon$, $\lambda$-topology induced by $\mathscr{F}^{i}$. Then the $\varepsilon$, $\lambda$-topology on $S$ induced by $F$ is the product topology.

Proof. Since $T_{m}$ is continuous the system of neighborhoods $B=$ $\left\{N_{\bar{p}}(\varepsilon, \lambda) \mid \bar{p} \in S, \varepsilon, \lambda>0\right\}$, where $N_{\bar{p}}(\varepsilon, \lambda)=\left\{\bar{q} \mid \bar{q} \in S, F_{\overline{p q}}(\varepsilon)>1-\lambda\right\}$, is a basis for the $\varepsilon, \lambda$-topology in $(S, F)$. Similarly, for every $i \in N$, the system $B_{i}=\left\{N_{p}(\varepsilon, \lambda) \mid p \in S_{i}, \varepsilon, \lambda>0\right\}$ where $N_{p}(\varepsilon, \lambda)=\left\{q \mid q \in S_{i}\right.$, $\left.F_{p q}^{i}(\varepsilon)>1-\lambda\right\}$, is a basis for the $\varepsilon, \lambda$-topology in $\left(S_{i}, F^{i}\right)$. Thus we have to show that $B$ and the system of neighborhoods

$$
C=\left\{\prod_{i=1}^{n} N_{p_{i}}\left(\varepsilon_{i}, \lambda_{i}\right) \times \prod_{i=1}^{\infty} S_{i+n} \mid n \in N,\left(p_{1}, \cdots, p_{n}\right) \in \prod_{i=1}^{n} S_{i}\right\}
$$

which is a basis for the product topology in $S$, are equivalent.

Given $N_{\bar{p}}(\varepsilon, \lambda)$ in $B$, choose $k \in N$ such that $\lambda^{\prime}=1-(1-\lambda) / \sum_{i=1}^{k} 2^{-i}>0$ and note that $\lambda^{\prime}<1$ if $\lambda<1$. Then if $\bar{q} \in U=\prod_{i=1}^{k} N_{p_{i}}\left(\varepsilon, \lambda^{\prime}\right) \times$ $\prod_{i=1}^{\infty} S_{i+k}$ we have $F_{p_{i} q_{i}}(\varepsilon)>1-\lambda^{\prime}$, for $i=1,2, \cdots, k$. Thus

$$
F_{\bar{p} \bar{q}}(\varepsilon) \geqq \sum_{i=1}^{k} 2^{-i} F_{p_{i} q_{i}}(\varepsilon)>\sum_{i=1}^{k} 2^{-i}\left(1-\lambda^{\prime}\right)=1-\lambda,
$$

and $U \subset N_{\bar{p}}^{-}(\varepsilon, \lambda)$. In the other direction, let $V=\prod_{i=1}^{n} N_{p_{i}}\left(\varepsilon_{i}, \lambda_{i}\right) \times$ 
$\prod_{i=1}^{\infty} S_{i+n}$, where $0<\lambda_{i}<1$ for $i=1,2, \cdots, n$, be a given neighborhood in $C$. Choose $\varepsilon=\operatorname{Min}\left\{\varepsilon_{1}, \varepsilon_{2}, \cdots, \varepsilon_{n}\right\}$ and

$$
\lambda=1-\operatorname{Max}\left\{2^{-i}\left(1-\lambda_{i}\right)+\sum_{\substack{k=1 \\ k \neq i}}^{\infty} 2^{-k} \mid i=1, \cdots, n\right\} .
$$

If $\bar{q} \in N_{\bar{p}}(\varepsilon, \lambda)$, we have for each $i=1,2, \cdots, n$,

$$
\begin{aligned}
& F_{\overline{p q}}(\varepsilon)>1-\lambda=\operatorname{Max}\left\{2^{-i}\left(1-\lambda_{i}\right)+\sum_{\substack{k=1 \\
k \neq i}}^{\infty} 2^{-k} \mid i=1, \cdots, n\right\} \\
& \geqq 2^{-i}\left(1-\lambda_{i}\right)+\sum_{\substack{k=1 \\
k \neq i}}^{\infty} 2^{-k} F_{p_{k} q_{k}}(\varepsilon),
\end{aligned}
$$

whence

$$
F_{p_{i} q_{i}}\left(\varepsilon_{i}\right) \geqq F_{p_{i} q_{i}}(\varepsilon)>1-\lambda_{i}
$$

thus $N_{\bar{p}}(\varepsilon, \lambda) \subset V$, and the proof is complete.

Recalling some elementary theorems of general topology, it is immediate that the $\varepsilon, \lambda$-topology induced by $F$ on $S$ is the least topology making the projections $\pi_{i}: S \rightarrow S_{i}$ continuous for all $i \in N$. We also have:

CoROLLARY 1.2. If $\left(S^{\prime}, F^{\prime \prime}, \tau^{\prime}\right)$ is a $P M$ space with $\tau^{\prime} \geqq \tau_{T_{m}}$ then the mapping $f$ from $S^{\prime}$ into $\prod_{i=1}^{\infty} S^{\prime}$ given by $f(p)=(p)$ is an isometry and is continuous with respect to the $\varepsilon, \lambda$-topology.

From [5] we know that the $\varepsilon, \lambda$-topology of a PM space with an Archimedean $t$-norm $T$ is metrizable by the metrics $d_{z}(p, q)=$ $-\log C_{T} F_{p q}(z)$, for any $z>0$, where $C_{T}$ is the $T$-conjugate transform for the semigroup $\left(\Delta^{+}, \tau_{T}\right)$, i.e., $C_{T}$ is defined for any $F \in \Delta^{+}$via:

$$
C_{T} F(z)=\sup _{x \geq 0} e^{-x z} h F(x), \text { for all } z \geqq 0,
$$

where $h$ is a fixed multiplicative generator of $T$ and $h F \in \Delta^{+}$is given by

$$
h F(x)= \begin{cases}0, & x \leqq 0 \\ h(F(x)), & 0<x\end{cases}
$$

Combining this with Theorem 1.2 and using the $T_{m}$-conjugate transform $\left(h(x)=e^{x-1}\right)$, we obtain:

CoROLlary 1.3. The product topology in $S$ is metrizable by the metric $d_{z}(\bar{p}, \bar{q})=-\log \sup _{x \geqq 0} \exp \left(\sum_{i=1}^{\infty} 2^{-i}\left(F_{p_{i} q_{i}}(x)-z x-1\right)\right)$, for 
any $z>0$. This metric is equivalent to the metric $d^{\prime}(\bar{p}, \bar{q})=$ $\sum_{i=1}^{\infty} 2^{-i} \operatorname{Min}\left[-\log \sup _{x \geqq 0} \exp \left(F_{p_{i} q_{i}}(x)-z_{i} x-1\right), 1\right]$, where $z_{i}>0$ for all $i \in N$.

\section{On $\tau$-products.}

Definition 2.1. Let $\left\{\left(S_{i}, \mathscr{F}^{i}, \tau_{i}\right) \mid i \in N\right\}$ be a countable family of PM spaces. The $\tau$-product is the space $\left(\prod_{i=1}^{\infty} S_{i}, G\right)$, where $G: \prod_{i=1}^{\infty} S_{i} \times \prod_{i=1}^{\infty} S_{i} \rightarrow \Delta^{+}$, is the mapping given by $G\left(\left(p_{i}\right),\left(q_{i}\right)\right)=$ $\tau_{i=1}^{\infty} \mathscr{F}^{i}\left(p_{i}, q_{i}\right)=w-\lim _{n \rightarrow \infty} \tau\left(\mathscr{F}^{1}\left(p_{1}, q_{1}\right), \cdots, \mathscr{F}^{n}\left(p_{n}, q_{n}\right)\right)$, for any sequences $\left(p_{i}\right),\left(q_{i}\right)$ in $\prod_{i=1}^{\infty} S_{i}$.

As in the preceding section, we adopt the conventions, $S=$ $\prod_{i=1}^{\infty} S_{i}, G_{\overline{p q}}=G\left(\left(p_{i}\right),\left(q_{i}\right)\right), F_{p_{i} q_{i}}=\mathscr{F}^{i}\left(p_{i}, q_{i}\right)$.

Theorem 2.1. If each of the PM spaces $\left(S_{i}, \mathscr{F}^{i}, \tau_{i}\right)$ is such that $\tau_{i} \geqq \tau$, where $\tau$ is a continuous triangle function, then the $\tau$-product $(S, G)$ is a $P M$ space under $\tau$.

Proof. If $G_{\overline{p q}}=\varepsilon_{0}$ then $F_{p_{i} q_{i}}=\varepsilon_{0}$, for any $i$, so $\left(p_{i}\right)=\left(q_{i}\right)$. Conversely $G_{\bar{p} q}=\tau_{i=1}^{\infty} \varepsilon_{0}=\varepsilon_{0}$. The symmetry of $G$ is obvious and the triangle inequality follows from

$$
\begin{aligned}
& \tau\left(G_{\bar{p} \bar{q}}, G_{\bar{q} \bar{r}}^{-}\right)=\tau\left(w-\lim _{n \rightarrow \infty} \tau\left(F_{p_{1} q_{1}}, \cdots, F_{p_{n} q_{n}}\right), w-\lim _{n \rightarrow \infty} \tau\left(F_{q_{1} r_{1}}, \cdots, F_{q_{n} r_{n}}\right)\right) \\
& =w-\lim _{n \rightarrow \infty} \tau_{i=1}^{n} \tau\left(F_{p_{i} q_{i}}, F_{q_{i} r_{i}}\right) \leqq w-\lim _{n \rightarrow \infty} \tau_{i=1}^{n} \tau_{i}\left(F_{p_{i} q_{i}}, F_{q_{i} r_{i}}\right) \\
& \leqq w-\lim _{n \rightarrow \infty}{\underset{i=1}{n}}_{i}^{n} F_{p_{i} r_{i}}=G_{\bar{p} \bar{r}} .
\end{aligned}
$$

At first this result, which is a straightforward generalization from finite products to countably infinite ones, seems to be satisfactory. However, two difficulties arise immediately. The first is the fact that since the sequence $\left\{\tau_{i=1}^{n} F_{p_{i} q_{i}} \mid n \in N\right\}$ is nonincreasing its weak limit may be zero everywhere, i.e., the infinite product may diverge. This question has recently been studied by $R$. Moynihan [4]. The second difficulty is of a topological nature.

THEOREM 2.2. Let each of the PM spaces $\left(S_{i}, \mathscr{F}^{i}, \tau_{i}\right)$ be endowed with the $\varepsilon$, ג-topology. Then the product topology is weaker than the $\varepsilon, \lambda$-topology in $(S, G)$.

Proof. Let $U=\prod_{i=1}^{n} N_{p_{i}}\left(\varepsilon_{i}, \lambda_{i}\right) \times \prod_{i=n+1}^{\infty} S_{i}$ be a standard neighborhood in the product topology. Choose $\varepsilon=\operatorname{Min}\left\{\varepsilon_{1}, \cdots, \varepsilon_{n}\right\}, \lambda=$ $\operatorname{Min}\left\{\lambda_{1}, \cdots, \lambda_{n}\right\}$ and let $\bar{q} \in N_{\bar{p}}(\varepsilon, \lambda)$. Then, since $G_{\bar{p} \bar{q}} \leqq F_{p_{i} q_{i}}$ for all 
$i$, we have $1-\lambda_{i} \leqq 1-\lambda<G_{\overline{p q}}^{-}(\varepsilon) \leqq F_{p_{i} q_{i}}(\varepsilon) \leqq F_{p_{i} q_{i}}\left(\varepsilon_{i}\right)$. Whence $N_{\bar{p}}^{-}(\varepsilon, \lambda) \subset \prod_{i=1}^{\infty} N_{p_{i}}(\varepsilon, \lambda) \subset U$.

From the above proof it is clear that, in general, the two topologies are not equal. For if this were the case, given $N_{\bar{p}}(\varepsilon, \lambda)$ there would exist a product neighborhood $U=\prod_{i=1}^{m} N_{p_{i}}\left(\varepsilon_{i}, \lambda_{i}\right) \times$ $\prod_{i=1}^{\infty} S_{i+m}$ such that $U \subset N_{\bar{p}}(\varepsilon, \lambda) \subset \prod_{i=1}^{\infty} N_{p_{i}}(\varepsilon, \lambda)$, which implies that $S_{i}=N_{p_{i}}(\varepsilon, \lambda)$ for all $i \geqq m$, a very strong condition. It follows that statements such as Corollary 1.2 also fail in general.

The reason for the difference between Theorems 1.4 and 2.2 is easily understood if one pays attention to the probabilistic interpretation of the $\varepsilon, \lambda$-neighborhoods in the respective products spaces: If $N_{\bar{p}}(\varepsilon, \lambda)$ is a neighborhood in the $\Sigma$-product then $\left(q_{i}\right) \in N_{\bar{p}}(\varepsilon, \lambda)$ implies that, with probability greater than $1-\lambda$, at least one of the $p_{i}$ is at a distance less than $\varepsilon$ from the corresponding $q_{i}$. On the other hand, if $N_{\bar{p}}(\varepsilon, \lambda)$ is a neighborhood in the $\tau$-product, and $\left(q_{i}\right) \in N_{\bar{p}}(\varepsilon, \lambda)$ then, with probability greater than $1-\lambda$, all the $p_{i}$ are at a distance less than $\varepsilon$ from the corresponding $q_{i}$.

3. Algebraic convexifications. For a $\mathrm{PM}$ space $(S, \mathscr{F}, \tau)$ the Wald-betweenness relation which is defined by $W(p, q, r)$ if and only if $\tau\left(F_{p q}, F_{q r}\right)=F_{p r}$ has recently been studied in [5]. In accordance with the concepts developed there, we make the following:

Definition 3.1. A probabilistic semi-metric space is $\tau$-convex if, for every pair of distinct points $p, r$ in $S$, there exists a point $q$ $S, p \neq q \neq r$, such that $\tau\left(F_{p q}, F_{q r}\right)=F_{p r}$.

DeFinition 3.2. An algebraic convexification [12] of a PM space $(S, \mathscr{F}, \tau)$ is any extension of this space which is $\tau$-convex.

THEOREM 3.1. If $(S, \mathscr{F})$ is a probabilistic semi-metric space, then there exists an extension $\left(S^{*}, \mathscr{F}^{*}\right)$ which is $\Pi_{T_{m}}{ }^{-c o n v e x .}$

Proof. For any $\bar{p}(n)=\left(p_{1}, p_{2}, \cdots, p_{n}\right)$ in $S^{n}$, let $\left(\bar{p}(n),{ }^{*}\right)$ denote the element of $\prod_{i=1}^{\infty} S$ obtained by repeating the finite string $\bar{p}(n)$ infinitely often: thus $\left(\bar{p}(n),{ }^{*}\right)=\left(p_{1}, p_{2}, \cdots, p_{n}, p_{1}, p_{2}, \cdots, p_{n}, \cdots\right)$. Let

$$
S^{*}=\left\{\left(\bar{p}\left(2^{k}\right),{ }^{*}\right) \mid k \in N \text { and } \bar{p}\left(2^{k}\right) \in S^{2^{k}}\right\} \text {. }
$$

In the $\Sigma$-product $\left(\prod_{i=1}^{\infty} S, \mathscr{F}\right)$ let $F^{*}$ be the restriction of $F$ to $S^{*} \times S^{*}$ and $f: S \rightarrow S^{*}$ the injection given by $f(p)=(p, p, p, \cdots)$. Note that $f$ is distance preserving in the sense that $F_{p q}=F_{f(p) f(q)}^{*}$ for any $p, q \in S$. Thus $\left(S^{*}, \mathscr{F}^{*}\right)$ is an extension of $(S, \mathscr{F})$. To establish the $\Pi_{T_{m}}$-convexity of $S^{*}$ let $\bar{p}\left(2^{i}\right)=\left(p_{1}, p_{2}, \cdots, p_{2^{i}}\right)$ and 
$\bar{r}\left(2^{j}\right)=\left(r_{1}, r_{2}, \cdots, r_{2^{j}}\right)$ be any two fixed elements of $S^{2^{i}}$ and $S^{2^{j}}$, respectively, and assume, without loss of generality, that $i \leqq j$. Let $\alpha=\left(\bar{p}\left(2^{i}\right),{ }^{*}\right)$ and $\gamma=\left(\bar{r}\left(2^{j}\right),{ }^{*}\right)$; and note that $\alpha=\gamma$ if and only if $\bar{r}\left(2^{j}\right)$ is the string obtained by repeating the string $\bar{p}\left(2^{i}\right)$ exactly $2^{j-i}$ times. Now suppose $\alpha \neq \gamma$. Let

$$
\bar{q}\left(2^{j+1}\right)=\overbrace{\left(\bar{p}\left(2^{i}\right), \cdots, \bar{p}\left(2^{i}\right)\right.}^{2^{i-j} \text { times }}, \bar{r}\left(2^{j}\right))
$$

and let $\beta=\left(\bar{q}\left(2^{j+1}\right),{ }^{*}\right)$. If $\beta=\alpha$ then, as one readily sees, $\alpha=\gamma$, which cannot be. Thus $\beta \neq \alpha$ and, similarly $\beta \neq \gamma$. Since $\bar{q}\left(2^{j+1}\right)$ breaks up into two strings, each of length $2^{j}$, it follows that for any $k \in N$, either $\beta_{k}=\alpha_{k}$ or $\beta_{k}=\gamma_{k}$, whence we have that for any $x>0, F_{\alpha_{k} \beta_{k}}(x)+F_{\beta_{k} \gamma_{k}}(x)-1$ is equal to either $F_{\beta_{k} \gamma_{k}}(x)$ or $F_{\alpha_{k} \beta_{k}}(x)$. An appeal to Definition 1.1 then yields that $T_{m}\left(F_{\alpha \beta}^{*}(x), F_{\beta \gamma}^{*}(x)\right)=F_{\alpha \gamma}^{*}(x)$, i.e., $\Pi_{T_{m}}\left(F_{\alpha \beta}^{*}, F_{\beta \gamma}^{*}\right)=F_{\alpha \gamma}^{*}$.

CoRollaRY 3.1. For each $P M$ space, $\left(S, \mathscr{F}, \Pi_{T_{m}}\right)$, there exists a convex extension $\left(S^{*}, \mathscr{F}^{*}, \Pi_{T_{m}}\right)$.

An analogous result also holds for $\tau$-products (that is again subject to the defect that the infinite $\tau$-products involved may diverge).

THEOREM 3.2. Let $(S, \mathscr{F}, \tau)$ be a PM space with $\tau$ continuous. Then there exists a pair of mappings $(f, g)$ from $(S, \mathscr{F}, \tau)$ into a $\tau$-convex PM space $\left(S^{*}, \mathscr{F}^{*}, \tau\right)$ such that $f: S \rightarrow S^{*}$ is an injection and $g: \Delta^{+} \rightarrow \Delta^{+}$is a $\tau$-morphism that satisfies $\mathscr{F}^{*} \circ f \times f=g \circ \mathscr{F}$.

Proof. Consider the space $S^{*}$ constructed in Theorem 3.1 endowed with the relative structure of the $\tau$-product $\left(\prod_{i=1}^{\infty} S, G, \tau\right)$. Let $f: S \rightarrow S^{*}$ be the injection defined in the preceding proof; and let $g: \Delta^{+} \rightarrow \Delta^{+}$be given by $g(F)=\tau_{i=1}^{\infty} F$, for every $F \in \Delta^{+}$. Clearly the pair $(f, g)$ satisfies the required properties. Let $\alpha, \beta, \gamma$ be as in the preceding proof. As above, for any $k \in N$, either $\beta_{k}=\alpha_{k}$ or $\beta_{k}=\gamma_{k}$, so that, $\tau\left(F_{\alpha_{k} \beta_{k}}, F_{\beta_{k} \gamma_{k}}\right)=F_{\alpha_{k} \gamma_{k}}$. Since $\tau$ is continuous, we have

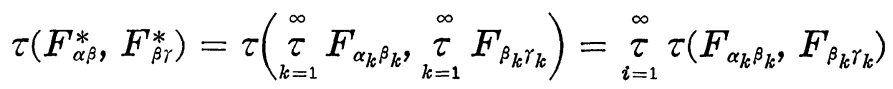

$$
\begin{aligned}
& ={\underset{i=1}{\infty}}_{\tau_{\alpha_{k} \gamma_{k}}}=F_{\alpha \gamma}^{*},
\end{aligned}
$$

whence $\left(S^{*}, \mathscr{F}^{*}, \tau\right)$ is $\tau$-convex. 


\section{REFERENCES}

1. R. J. Egbert, Products and quotients of probabilistic metric spaces, Pacific J. of Math., 24 (1968), 437-455.

2. V. Istratescu and I. Vaduva, Products of statistical metric spaces, Acad. R. P. Roumaine Stud. Cerc. Math., 12 (1961), 567-574.

3. K. Menger, Statistical metrics, Proc. Nat. Acad. Sci. U.S.A., 28 (1942), 535-537.

4. R. Moynihan, Infinite $\tau_{T}$ products of probability distribution functions, (to appear).

5. R. Moynihan and B. Schweizer, Betweenness relations in probabilistic metric spaces, (to appear).

6. B. Schweizer, Probabilistic metric spaces-The first 25 years, The New York Statistician, 19 (1967), 3-6.

7. B. Schweizer and A. Sklar, Statistical metric spaces, Pacific J. Math., 10 (1960), 313-334.

8. B. Schweizer, Multiplications on the space of probability distribution functions, Aeq. Math., 12 (1975), 151-183.

9. H. Sherwood and M. D. Taylor, Some PM structures on the set of distribution functions, Rev. Roum. Math. Pures et Appl., 19 (1974), 1251-1260.

10. R. Tardiff, Topologies for probabilistic metric spaces, Pacific J. Math., 65 (1976), 233-251.

11. E. Trillas, Sobre distancias estadísticas, Thesis, Pub. Univ. Barcelona (1972).

12. E. Trillas, C. Alsina and N. Batle, Espacios métricos generalizados de Riesz, (unpub.) (1968).

13. A. F. S. Xavier, On the product of probabilistic metric spaces, Portugal, Math., 27 (1976), 137-147.

Received April 13, 1977 and in revised form July 19, 1977. I want to thank B. Schweizer (U. Massachusetts) and E. Trillas (U. Politécnica Barcelona, Spain) for their suggestions in the preparation of this manuscript. This research was supported by a grant of the Ministerio de Educación y Ciencia (Spain) through the Universidad Politécnica de Barcelona (Spain).

UNIVERSITY OF MASSACHUSETTS

AMHERST, MA 01003 


\section{PACIFIC JOURNAL OF MATHEMATICS}

\section{EDITORS}

RICHARD ARENS (Managing Editor)

University of California

Los Angeles, CA 90024

Charles W. Curtis

University of Oregon

Eugene, OR 97403

C. C. MOORE

University of California

Berkeley, CA 94720

\section{J. DugundJI}

Department of Mathematics

University of Southern California

Los Angeles, CA 90007

R. FinN and J. Milgram

Stanford University

Stanford, CA 94305

\section{ASSOCIATE EDITORS}
E. F. BECKENBACH
B. H. NeumanN
F. WOLF
K. YosHIDA

\section{SUPPORTING INSTITUTIONS}

\author{
UNIVERSITY OF BRITISH COLUMBIA \\ CALIFORNIA INSTITUTE OF TECHNOLOGY \\ UNIVERSITY OF CALIFORNIA \\ MONTANA STATE UNIVERSITY \\ UNIVERSITY OF NEVADA, RENO \\ NEW MEXICO STATE UNIVERSITY \\ OREGON STATE UNIVERSITY \\ UNIVERSITY OF OREGON
}

\author{
UNIVERSITY OF SOUTHERN CALIFORNIA \\ STANFORD UNIVERSITY \\ UNIVERSITY OF HAWAII \\ UNIVERSITY OF TOKYO \\ UNIVERSITY OF UTAH \\ WASHINGTON STATE UNIVERSITY \\ UNIVERSITY OF WASHINGTON
}

The Supporting Institutions listed above contribute to the cost of publication of this Journal, but they are not owners or publishers and have no responsibility for its content or policies.

Mathematical papers intended for publication in the Pacific Journal of Mathematics should be in typed form or offset-reproduced, (not dittoed), double spaced with large margins. Please do not use built up fractions in the text of the manuscript. However, you may use them in the displayed equations. Underline Greek letters in red, German in green, and script in blue. The first paragraph or two must be capable of being used separately as a synopsis of the entire paper. Items of the bibliography should not be cited there unless absolutely necessary, in which case they must be identified by author and journal, rather than by item number. Manuscripts, in triplicate, may be sent to any one of the editors. Please classify according to the scheme of Math. Reviews, Index to Vol. 39. All other communications should be addressed to the managing editor, or Elaine Barth, University of California, Los Angeles, California, 90024.

50 reprints to each author are provided free for each article, only if page charges have been substantially paid. Additional copies may be obtained at cost in multiples of 50 .

The Pacific Journal of Mathematics is issued monthly as of January 1966. Regular subscription rate: $\$ 72.00$ a year (6 Vols., 12 issues). Special rate: $\$ 36.00$ a year to individual members of supporting institutions.

Subscriptions, orders for numbers issued in the last three calendar years, and changes of address should be sent to Pacific Journal of Mathematics, 103 Highland Boulevard, Berkeley, California, 94708. Older back numbers obtainable from Kraus Periodicals Co., Route 100, Millwood, NY 10546.

PUBLISHED BY PACIFIC JOURNAL OF MATHEMATICS, A NON-PROFIT CORPORATION

Printed at Kokusai Bunken Insatsusha (International Academic Printing Co., Ltd.). 8-8, 3-chome, Takadanobaba, Shinjuku-ku, Tokyo 160, Japan.

Copyright (C) 1978 by Pacific Journal of Mathematics Manufactured and first issued in Japan 


\section{Pacific Journal of Mathematics}

\section{Vol. 76, No. $2 \quad$ December, 1978}

Stephanie Brewster Brewer Taylor Alexander, Local and global convexity in complete Riemannian manifolds ...........................

Claudi Alsina i Català, On countable products and algebraic convexifications of probabilistic metric spaces ...............................

Joel David Berman and George Grätzer, Uniform representations of

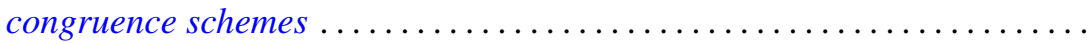

Ajit Kaur Chilana and Kenneth Allen Ross, Spectral synthesis in

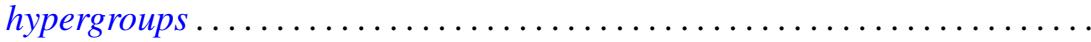

David Mordecai Cohen and Howard Leonard Resnikoff, Hermitian quadratic forms and Hermitian modular forms . .........................

Frank Rimi DeMeyer, Metabelian groups with an irreducible projective

representation of large degree .............................

Robert Ellis, The Furstenberg structure theorem .....................

Heinz W. Engl, Random fixed point theorems for multivalued mappings .......

William Andrew Ettling, On arc length sharpenings ..................

Kent Ralph Fuller and Joel K. Haack, Rings with quivers that are trees........

Kenneth R. Goodearl, Centers of regular self-injective rings ...............

John Gregory, Numerical algorithms for oscillation vectors of second order

differential equations including the Euler-Lagrange equation for

symmetric tridiagonal matrices.

Branko Grünbaum and Geoffrey Shephard, Isotoxal tilings

Myron Stanley Henry and Kenneth Leroy Wiggins, Applications of

approximation theory to differential equations with deviating

arguments

Mark Jungerman, The non-orientable genus of the n-cube .

Robert Richard Kallman, Only trivial Borel measures on $S_{\infty}$ are

quasi-invariant under automorphisms ................

Joyce Longman and Michael Rich, Scalar dependent algebras in the

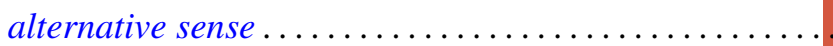

Richard A. Mollin, The Schur group of a field of characteristic zero ........ 471

David Pokrass, Some radical properties of rings with $(a, b, c)=(c, a, b) \ldots 479$

Margaret Shay and Paul Ruel Young, Characterizing the orders changed by

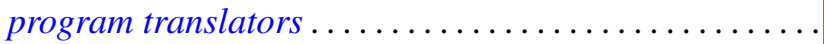

Jerrold Norman Siegel, On the structure of $B_{\infty}(F), F$ a stable space...

Surjeet Singh, (hnp)-rings over which every module admits a basic

submodule...

A. K. Snyder, Universal interpolating sets and the Nevanlinna-Pick property in

Banach spaces of functions...

Jeffrey D. Vaaler, On the metric theory of Diophantine approximation ... 